Article

\title{
Tyrosine Kinase Inhibitors Improved Survival of Critically Ill EGFR-Mutant Lung Cancer Patients Undergoing Mechanical Ventilation
}

\author{
I-Hsien Lee ${ }^{1}$, Ching-Yao Yang ${ }^{2, *(\mathbb{D})}$, Jin-Yuan Shih ${ }^{2} \mathbb{D}$ and Chong-Jen $\mathrm{Yu}^{2}(\mathbb{D}$ \\ 1 Department of Emergency and Critical Care Medicine, Fu-Jen Catholic University Hospital, \\ New Taipei City 24308, Taiwan; qqcu111@gmail.com \\ 2 Division of Thoracic Medicine, Department of Internal Medicine, National Taiwan University Hospital, \\ Taipei 10225, Taiwan; jyshih@ntu.edu.tw (J.-Y.S.); jefferycjyu@ntu.edu.tw (C.-J.Y.) \\ * Correspondence: chingyao.yang@gmail.com
}

check for

updates

Citation: Lee, I.-H.; Yang, C.-Y.; Shih, J.-Y.; Yu, C.-J. Tyrosine Kinase Inhibitors Improved Survival of Critically Ill EGFR-Mutant Lung Cancer Patients Undergoing Mechanical Ventilation. Biomedicines 2021, 9, 1416. https://doi.org/ $10.3390 /$ biomedicines 9101416

Academic Editors: Massimo Moro and Luca Falzone

Received: 11 September 2021

Accepted: 5 October 2021

Published: 8 October 2021

Publisher's Note: MDPI stays neutral with regard to jurisdictional claims in published maps and institutional affiliations.

Copyright: (c) 2021 by the authors. Licensee MDPI, Basel, Switzerland. This article is an open access article distributed under the terms and conditions of the Creative Commons Attribution (CC BY) license (https:/ / creativecommons.org/licenses/by/ $4.0 /)$.

\begin{abstract}
Background: Respiratory failure requiring mechanical ventilation is the major reason for lung cancer patients being admitted to the intensive care unit (ICU). Though molecular targeted therapies, especially epidermal growth factor receptor (EGFR)-tyrosine kinase inhibitors (TKIs), have largely improved the survival of oncogene-driven lung cancer patients, few studies have focused on the performance of TKI in such settings. Materials and Methods: This was a retrospective cohort study enrolling non-small cell lung cancer (NSCLC) patients who harbored sensitizing EGFR mutation and had received EGFR-TKIs as first-line cancer therapy in the ICU with mechanical ventilator use. The primary outcome was the 28-day ICU survival rate, and secondary outcomes were the rate of successful weaning from the ventilator and overall survival. Results: A total of 35 patients were included. The 28-day ICU survival rate was $77 \%$, and the median overall survival was 67 days. Multivariate logistic regression revealed that shock status was associated with a lower 28-day ICU survival rate independently (odds ratio (OR) 0.017, 95\% confidence interval (CI), 0.000-0.629, $p=0.027$ ), and that L858R mutation (L858R compared with exon 19 deletion, OR, 0.014, 95\% CI $0.000-0.450, p=0.016)$ and comorbidities of diabetes mellitus (DM) (OR, 0.032, 95\% CI, 0.000-0.416, $p=0.014)$ ) were independently predictive of weaning failure. The successful weaning rate was $43 \%$, and the median of ventilator-dependent duration was 22 days (IQR, 12-29). Conclusions: For EGFR mutant lung cancer patients suffering from respiratory failure and undergoing mechanical ventilation, TKI may still be useful, especially in those with EGFR del19 mutation or without shock and DM comorbidity.
\end{abstract}

Keywords: EGFR; lung cancer; critical care; mechanical ventilation; tyrosine kinase inhibitor

\section{Introduction}

Lung cancer patients account for $8 \%$ of all intensive care unit (ICU) admissions of patients with malignancies and $27 \%$ of those with solid cancer [1,2]. However, lung cancer patients have experienced worse ICU outcomes than those with other solid cancers. Data from the Surveillance, Epidemiology, and End Results (SEER) Medicare registry (1992 to $2007, \mathrm{~N}=49,373$ ) revealed that $65 \%$ of patients with lung cancer died within 6 months after ICU admission [3]. A recent large multi-center retrospective cohort study reported modest improvements in lung cancer patient survival-they found that 449 patients admitted to 22 ICUs in Europe and Latin America had 6-month survival rates between $40 \%$ and $50 \%$ [4]. Patients with a non-progressive malignancy and good performance status (PS score $\leq 2$ ) [4] had a better prognosis. Although the outcomes of patients with lung cancer admitted to the ICU in different studies varied, overall ICU mortality was around 50\%. The use of mechanical ventilation (MV) for lung cancer patients who developed acute respiratory failure was associated with a mortality rate of over $70 \%[3,5,6]$. Treating patients 
with advanced non-small-cell lung cancer (NSCLC) using chemotherapy in the ICU is controversial because a PS score $>2$ is considered to be a contraindication for chemotherapy administration, and NSCLC is usually less sensitive to chemotherapeutic drugs [7]. By the mid-2000s, ICU admission for life-threatening events was still widely viewed as unlikely to benefit these patients, particularly when ventilator support is needed [8].

However, in the 21st century, targeted therapy has dramatically changed the management of NSCLC. In 2009, a landmark trial described a "Lazarus" response in NSCLC patients with a PS of 34-a dramatic improvement in PS was found in $70 \%$ of patients who harbored an EGFR mutation $[9,10]$. Tumors that harbor EGFR mutations can exhibit dramatic responses to an EGFR-tyrosine-kinase inhibitor (TKI), such as gefitinib, erlotinib, afatinib, or osimertinib [11-14]. However, there is limited evidence suggesting the use of TKI in EGFR-mutant lung cancer patients who suffer from respiratory failure and need ICU admission. A few case series exist regarding the use of targeted therapy for patients with NSCLC in the ICU [6,15-19]. Besides targeted therapies, immune checkpoint inhibitors have also refined the paradigm of lung cancer treatment in the past decade, especially in patients with high programmed death-ligand 1 (PD-L1) expression [20,21]. Unlike chemotherapy or small molecule inhibitors, immunotherapy further improved long-term survival in a subset of patients, making a long tail in the overall survival curve [22]. However, the effectiveness of immunotherapy is probably limited in patients suffering from critical illness, who are mostly in an immunocompromised status [23-25].

Since targeted therapy has better efficacy and fewer treatment-related side effects, namely, it is more tolerable for patients even in a critical status, compared to cytotoxic chemotherapy, treating ICU patients with EGFR-TKIs if the sensitizing mutation is identified could be a reasonable approach. In this study, we aimed to analyze the performance of TKI with lung cancer patients admitted to the ICU due to respiratory failure and who required $\mathrm{MV}$, and of whom all had an available EGFR mutation status.

\section{Materials and Methods}

\subsection{Study Design and Patient Population}

This was a single-center retrospective study, conducted from 2010 to 2018 at National Taiwan University Hospital, which has 5 medical ICUs and a total of 49 beds. The inclusion criteria were as follows: advanced NSCLC, available EGFR mutation status, admission to the ICU with respiratory failure and undergoing MV, use of EGFR-TKIs during ICU hospitalization, and no tumor progression if the EGFR-TKI was given before ICU admission. The study was approved by the Research Ethics Committee of our hospital (201802015RINB).

\subsection{Data Collection and Outcome}

After enrollment, demographics and baseline characteristics such as age, sex, comorbidity, ICU admission diagnosis, and illness severity upon ICU admission (APACHE II score) were recorded for all patients. Other clinical data including cancer stage, lung cancer histologic type (NSCLC), molecular status, and metastases sites were recorded. The primary reasons for ICU admission were categorized as pulmonary, septic shock, cardiac, or neurological. The treatments given in the ICU, including MV, vasopressor, dialysis, and do not resuscitate (DNR) orders, were recorded. The types and duration of EGFR-TKIs for lung cancer treatment were also recorded. The primary end point was 28th day survival in the ICU. Other secondary end points included discharge status from the ICU, 28th day mortality in the hospital, discharge status from the hospital, and MV weaning results.

\subsection{Detection of EGFR Mutations}

The preservation and preparation for the biopsied tumors were all formalin-fixed paraffin-embedded (FFPE) specimens. Mutational analysis of EGFR testing was performed in an ISO 15189-certificated central lab. Briefly, genomic DNA was extracted using the QIAmp DNA Minikit (QIAGEN, Redwood City, CA, USA), and the mutations were detected by the MassARRAY system (Agena, San Diego, CA, USA), based on the user manual. 
Extracted DNA was subjected to serial biochemical reactions, including 40 cycles of PCR, shrimp alkaline phosphatase (SAP) treatment, and 200 cycles of a signal nucleotide extension reaction. After cleaning using SpectroCLEAN resin, samples were loaded onto the matrix of a SpectroCHIP by Nanodispenser (Matrix), and then analyzed using Bruker Autoflex MALDI-TOF MS. Data were collected and analyzed using Typer4 software (Agena Bioscience, San Diego, CA, USA).

\subsection{Statistical Analysis}

Baseline demographics were compared between groups. All categorical variables were analyzed using Pearson's $\chi 2$ tests, except where a small sample size $(<5)$ required the use of Fisher's exact test. Continuous variables were analyzed using the Wilcoxon rank-sum test. Univariate and multivariate logistic regression was performed for 28-day ICU survival and weaning outcome. The odds ratios (ORs), 95\% confidence intervals (CIs), and $p$-values were reported. After univariate analysis, the factors with $p$-value $<0.1$ and with clinical importance were enrolled into multivariate analysis. ICU and days of MV use were compared by log-rank test and were plotted using Kaplan-Meier methods by the group of significant predictors. Statistical significance was set at a 2 -sided $p<0.05$. All analyses were performed using STATA version 15.0.

\section{Results}

\subsection{Patient Characteristics}

From 2010 to 2018, 176 patients admitted to the ICU with MV use and the diagnosis of NSCLC, and who were treated with EGFR-TKI, were enrolled. Fifty-one patients were excluded due to a lack of documentation of EGFR mutation status. Another 62 patients were excluded because of previous use of chemotherapy or other TKIs. Sixty-three patients who received EGFR-TKIs as first-line therapy for lung cancer, and among whom 35 harbored a sensitizing EGFR mutation were included. The median age of the patients was 73 years, $66 \%$ of the patients were female, and $77 \%$ were never-smokers. In terms of comorbidities, $9 \%$ of the patients had coronary artery disease or heart failure, and 17\% had COPD. The major reason for ICU admission and MV use was pneumonia (80\%). Most of the patients (34 of 35, 97\%) were diagnosed with adenocarcinoma, and 1 patient had sarcomatoid carcinoma. Ninety-seven percent of the patients had stage 4 lung cancer, according to the American Joint Committee on Cancer 7 th edition, and $23 \%$ had brain metastases. The mutation subtypes of the patients who had a sensitizing EGFR mutation were as follows: L858R: 15 (42.8\%), exon 19 deletion: 14 (40\%), and uncommon mutation: 6 (17.1\%). Mean APACHE II score of the patients was 25 (22-28) (Table 1). The CONSORT diagram is shown in Figure 1.

Table 1. Demographic data and treatment outcome of EGFR-TKI-treated NSCLC patients who were admitted to the ICU and received mechanical ventilation.

\begin{tabular}{ccc}
\hline EGFR Mutation $(\boldsymbol{n}=\mathbf{3 5})$ & \\
\hline Gender (Male/Female) & 12 & 23 \\
& $(34 \%)$ & $(66 \%)$ \\
\hline Age (median, range) & \multicolumn{2}{c}{$73(67-79)$} \\
Smokers $(n, \%)$ & 8 & $23 \%$ \\
APACHE II score & \multicolumn{2}{c}{$25(22-28)$} \\
Stage IV $(n, \%)$ & 34 & \multicolumn{2}{c}{$97 \%$} \\
Interval between cancer diagnosis and ICU admission (days) & \multicolumn{2}{c}{$134(6-546)$} \\
\hline
\end{tabular}


Table 1. Cont.

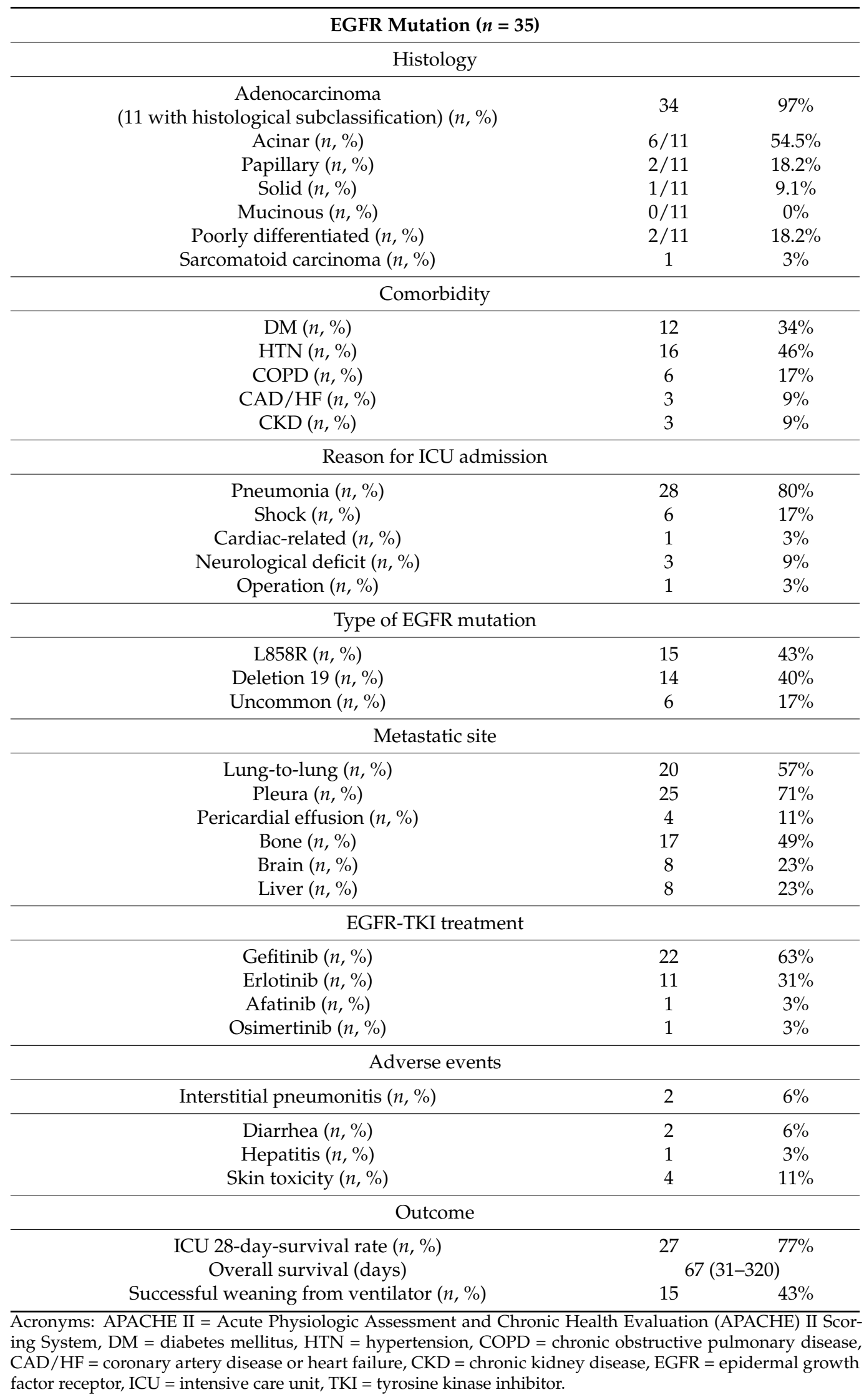




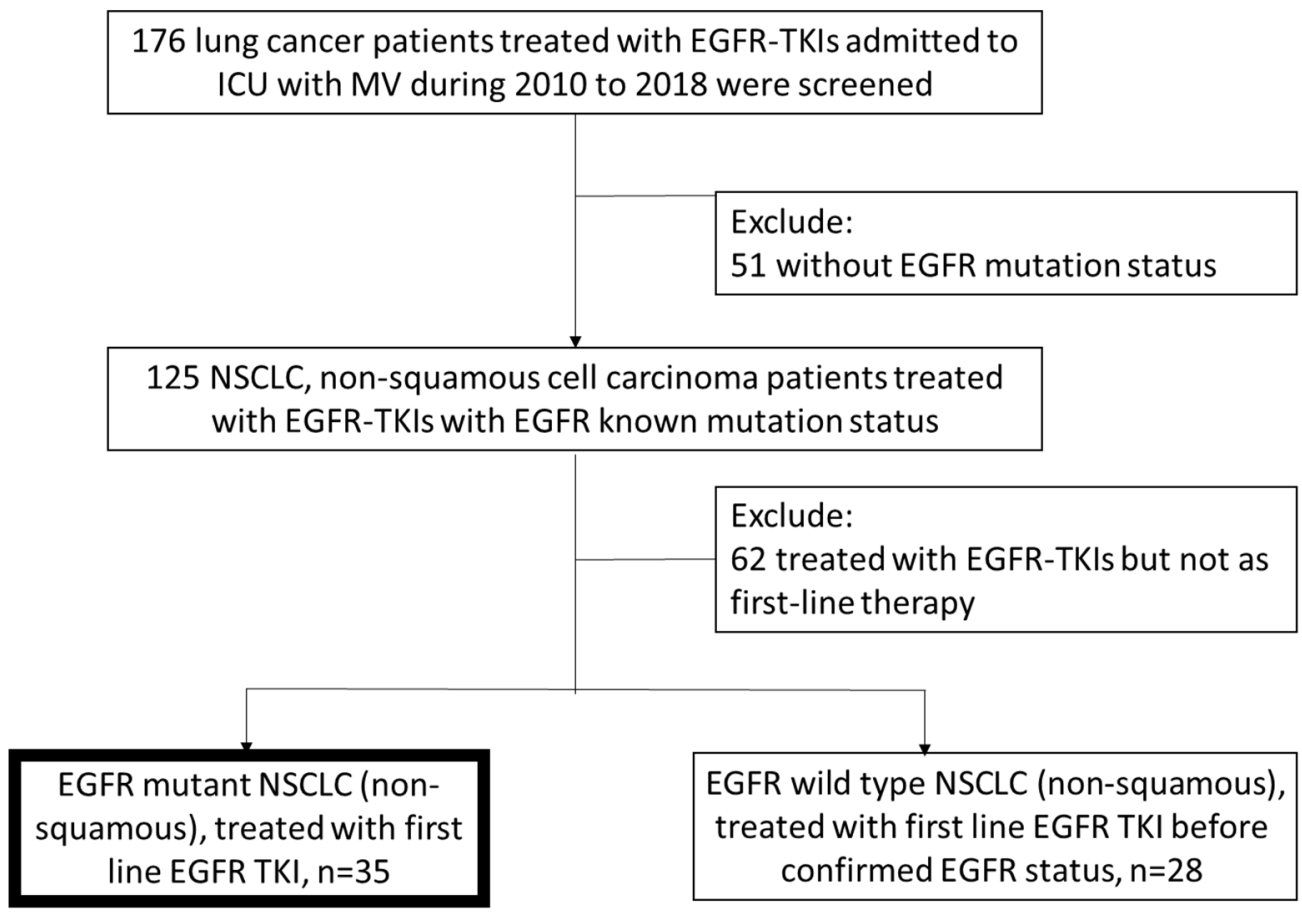

Primary analysis cohort

Figure 1. Consortium diagram of our study. Acronyms: EGFR = epidermal growth factor receptor, $\mathrm{ICU}=$ intensive care unit, $\mathrm{MV}=$ mechanical ventilation, NSCLC $=$ non-small cell lung cancer, TKI = tyrosine kinase inhibitor.

\subsection{Clinical Outcomes in the ICU}

Most of the patients were treated with a first- or second-generation EGFR-TKI (gefitinib: 22; erlotinib: 11; and afatinib: 1). Only one patient received osimertinib treatment in the ICU. The median duration for the use of EGFR-TKIs in the ICU was 17 days for patients with a sensitizing EGFR mutation.

The 28-day ICU survival rate was $77 \%$, and the median survival time was 67 days. Multivariate logistic regression revealed that shock status at ICU admission effectively predicted 28-day ICU survival (OR 0.017, 95\% CI, 0.000-0.629, $p=0.027$ ) (Table 2). The 28-day ICU survival curve is shown in Figure 2A. The log rank test showed significantly better 28 -day in patients without shock, with a $p$ value $<0.001$ (Figure 2B).

Table 2. Univariate and multivariate analysis of clinical factors associated with 28-day ICU survival.

\begin{tabular}{|c|c|c|c|c|}
\hline & Univariate & & Multivariate & \\
\hline & OR $(95 \% \mathrm{CI})$ & & OR $(95 \%$ CI) & $p$ Value \\
\hline \multicolumn{5}{|l|}{ Demographic factors } \\
\hline Age & $1.070(0.993-1.153)$ & 0.074 & $1.090(0.990-1.199)$ & 0.078 \\
\hline APACHE II & $0.555(0.117-2.634)$ & 0.459 & $0.982(0.834-1.157)$ & 0.830 \\
\hline Gender (male vs. female) & $1.054(0.934-1.189)$ & 0.397 & & \\
\hline Brain metastasis & $0.476(0.087-2.593)$ & 0.391 & & \\
\hline Liver metastasis & $1.051(0.171-6.462)$ & 0.958 & & \\
\hline \multicolumn{5}{|c|}{ EGFR mutation (based on Deletion 19) } \\
\hline L8585R & $0.688(0.124-3.786)$ & 0.667 & & \\
\hline Uncommon & $0.375(0.042-3.355)$ & 0.380 & & \\
\hline
\end{tabular}


Table 2. Cont.

\begin{tabular}{|c|c|c|c|c|}
\hline & Univariate & & Multivariate & \\
\hline & OR $(95 \%$ CI) & & OR (95\% CI) & $p$ Value \\
\hline \multicolumn{5}{|l|}{ Comorbidity } \\
\hline COPD & $0.167(0.023-1.232)$ & 0.079 & $0.139(0.011-1.764)$ & 0.128 \\
\hline $\mathrm{CAD} / \mathrm{HF}$ & $0.667(0.053-8.372)$ & 0.753 & & \\
\hline DM & $0.294(0.061-1.423)$ & 0.128 & & \\
\hline \multicolumn{5}{|c|}{ Reason for ICU admission } \\
\hline Shock & $0.167(0.023-1.232)$ & 0.079 & $0.017(0.000-0.629)$ & 0.027 \\
\hline Pneumonia & $0.277(0.029-2.637)$ & 0.264 & & \\
\hline
\end{tabular}

Acronyms: APACHE II = Acute Physiologic Assessment and Chronic Health Evaluation (APACHE) II Scoring System, CAD/HF = coronary artery disease or heart failure, $\mathrm{COPD}=$ chronic obstructive pulmonary disease, $\mathrm{DM}=$ diabetes mellitus, $\mathrm{EGFR}=$ epidermal growth factor receptor, ICU = intensive care unit.

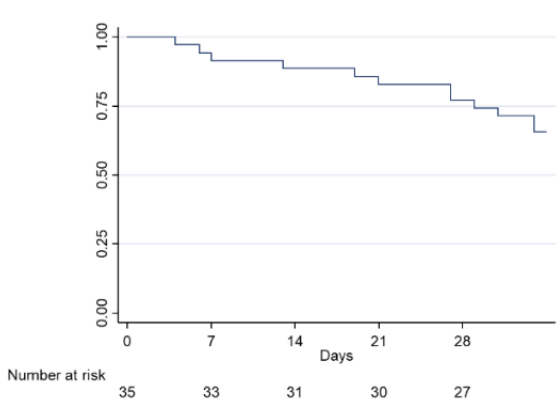

(A)

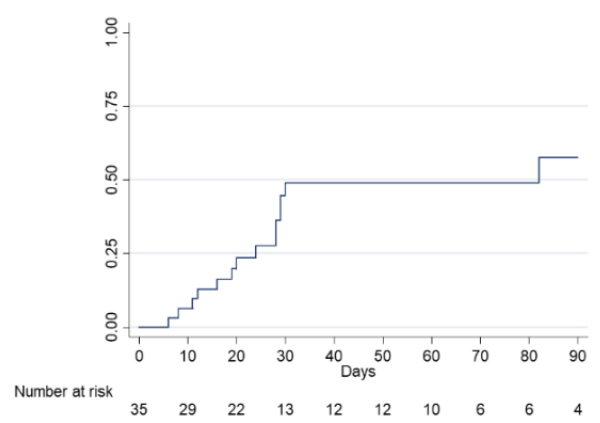

(C)

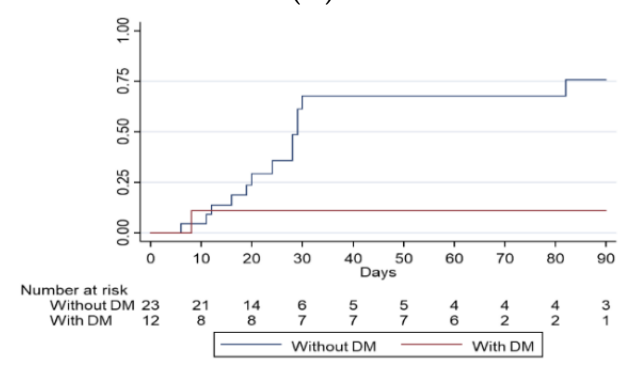

(E)

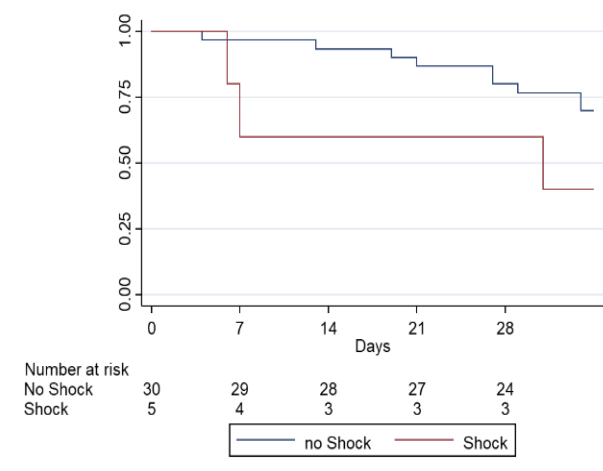

(B)

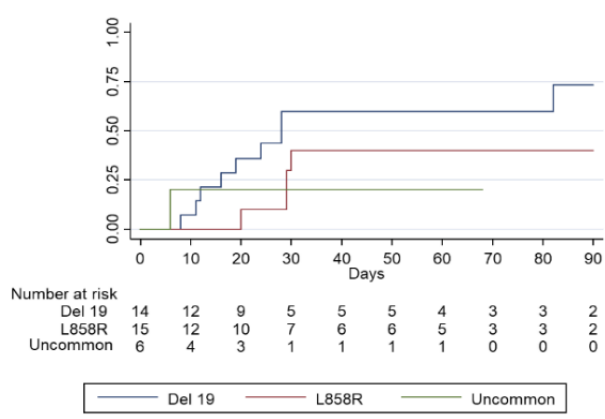

(D)

Figure 2. Survival and rate of successful weaning from mechanical ventilation of lung cancer patients receiving EGFR-TKIs in the ICU. (A) 28-day ICU survival. (B) Kaplan-Meier plot of survival in group with shock or not. (C) Cumulative incidence of patients with successful weaning from mechanical ventilators. (D) Cumulative incidence of successful weaning in patients with different EGFR mutation. (E) Cumulative incidence of successful weaning in patients with or without DM. Acronyms: EGFR = epidermal growth factor receptor, ICU = intensive care unit, TKI = tyrosine kinase inhibitor, $\mathrm{DM}=$ diabetes mellitus. 
In addition, $43 \%$ of the patients were successfully weaned from $\mathrm{MV}$, and the median days with MV use was 22 (IQR = 12-29) days (Figure 2C). The cumulative incidence of successful weaning rate was higher among the patients harboring EGFR deletion $19 \mathrm{mu}-$ tation than those with L858R or other uncommon mutations, with a log-rank $p$ value of 0.016 (Figure 2D); it was also higher in the patient without diabetes mellitus (DM) (log-rank $p$ value $<0.001$, Figure 2E). Multivariate logistic regression yielded that L858R (compared to Deletion 19, OR 0.014, 95\% CI 0.000-0.450, $p=0.016$ ) and DM (OR 0.014, 95\% CI 0.000-0.416, $p=0.014$ ) were independently predictive of weaning failure (Table 3 ).

Table 3. Univariate and multivariate analysis of clinical factors associated with successful MV weaning.

\begin{tabular}{|c|c|c|c|c|}
\hline & Univariate & & Multivariate & \\
\hline & OR (95\% CI) & & OR (95\% CI) & $p$ Value \\
\hline \multicolumn{5}{|l|}{ Demographic factors } \\
\hline Age & $1.019(0.920-1.046)$ & 0.559 & $0.900(0.791-1.026)$ & 0.112 \\
\hline APACHE II & $1.017(0.915-1.130)$ & 0.759 & $0.931(0.777-1.116)$ & 0.440 \\
\hline Gender (male vs. female) & $1.875(0.453-7.758)$ & 0.386 & & \\
\hline Brain metastasis & $0.873(0.172-4.429)$ & 0.870 & & \\
\hline Liver metastasis & $0.873(0.172-4.429)$ & 0.870 & & \\
\hline \multicolumn{5}{|c|}{ EGFR mutation (based on Deletion 19) } \\
\hline L8585R & $0.242(0.052-1.133)$ & 0.072 & $0.014(0.000-0.450)$ & 0.016 \\
\hline Uncommon & $0.167(0.015-1.879)$ & 0.147 & $0.032(0.001-1.358)$ & 0.072 \\
\hline \multicolumn{5}{|l|}{ Comorbidity } \\
\hline COPD & $1.000(0.145-6.907)$ & 1.000 & & \\
\hline $\mathrm{CAD} / \mathrm{HF}$ & $0.731(0.033-3.284)$ & 0.806 & & \\
\hline DM & $0.070(0.008-0.635)$ & 0.018 & $0.014(0.000-0.416)$ & 0.014 \\
\hline \multicolumn{5}{|l|}{ Reason for ICU admission } \\
\hline Shock & $0.327(0.033-3.284)$ & 0.342 & & \\
\hline Pneumonia & $2.014(0.363-11.187)$ & 0.423 & & \\
\hline
\end{tabular}

Acronyms: APACHE II = Acute Physiologic Assessment and Chronic Health Evaluation (APACHE) II Scoring System, CAD/HF = coronary artery disease or heart failure, $\mathrm{COPD}=$ chronic obstructive pulmonary disease, $\mathrm{DM}=$ diabetes mellitus, $\mathrm{EGFR}=$ epidermal growth factor receptor, ICU = intensive care unit.

Otherwise, there were 28 mechanically ventilated EGFR wild type lung cancer patients who also received EGFR TKI in ICU during our study period. Most of them stopped EGFR TKI treatments after the wild-type status had been confirmed, and the median duration of EGFR TKI of them was 8 days. The demographic data of these patients are shown in Supplementary Table S1. Compared to EGFR mutant cases, EGFR wild type patients had shorter 28-day, 90-day and overall survival (Supplementary Figure S1 and Table S2), and the successful weaning rate was only $25 \%$ (7 of 28 ).

Regarding TKI efficacy, there were only 16 of 35 patients receiving follow-up chest computed tomography (CT) to evaluate treatment response, though most of the CT scans were performed after ICU discharge. In EGFR mutant cases with evaluable CT results $(n=16)$, all showed partial response to EGFR TKI, but only 12 of 16 were successfully weaned from mechanical ventilation. In EGFR mutant cases without CT studies $(n=19), 3$ of 19 showed radiologically improvements in chest radiography, and all 3 patients were weaned from mechanical ventilation. The results are summarized in Table 4. 
Table 4. EGFR TKI treatment responses and weaning outcomes.

\begin{tabular}{|c|c|c|}
\hline & \multicolumn{2}{|c|}{ EGFR Mutation $(n=35)$} \\
\hline & Weaning Success & Weaning Failure \\
\hline \multicolumn{3}{|l|}{ CT image $(n=16)$} \\
\hline $\mathrm{CR} / \mathrm{PR}$ & 12 & 4 \\
\hline $\mathrm{SD} / \mathrm{PD}$ & 0 & 0 \\
\hline \multicolumn{3}{|c|}{ Chest radiography $(n=19)$} \\
\hline Improve & 3 & 0 \\
\hline Stable/Deteriorate & 0 & 16 \\
\hline \multicolumn{3}{|c|}{$\begin{array}{l}\text { Abbreviation: CR, complete response; } \mathrm{CT} \text {, computed tomography; EGFR, epidermal growth factor receptor; PD } \\
\text { progression of disease; SD, stable disease. }\end{array}$} \\
\hline \multicolumn{3}{|c|}{$\begin{array}{l}\text { We present an EGFR-mutant case that received EGFR-TKI treatment after ICU ad- } \\
\text { mission and subsequently experienced a remarkable response (Figure 3). Briefly, this } \\
\text { 72-year-old woman presented with respiratory failure due to tumor obstruction of the } \\
\text { right main bronchus and total collapse of the right lung. After 14-day gefitinib use, the } \\
\text { right main bronchus obstruction was resolved, and the patient was successfully weaned } \\
\text { from MV. }\end{array}$} \\
\hline
\end{tabular}

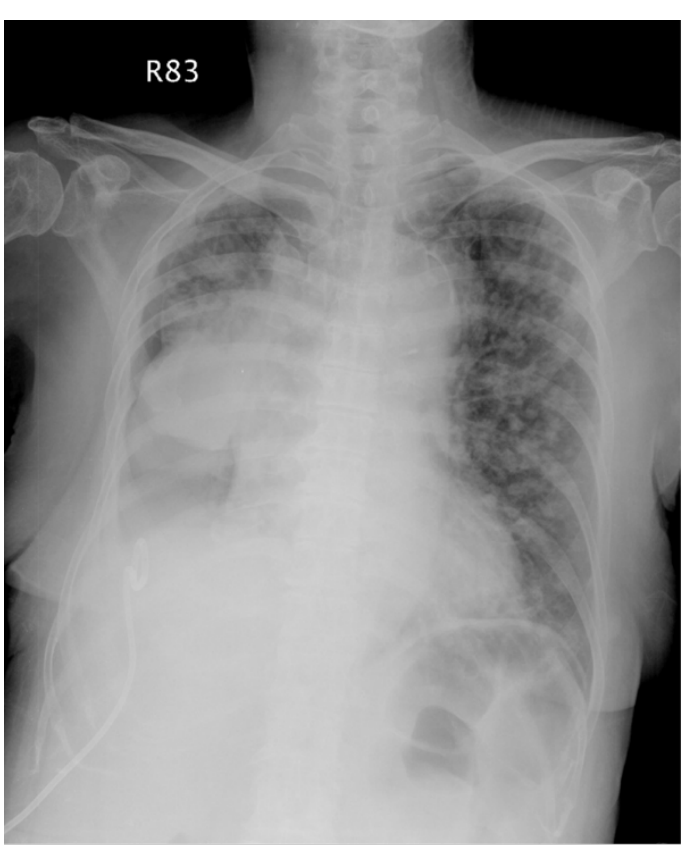

(A)

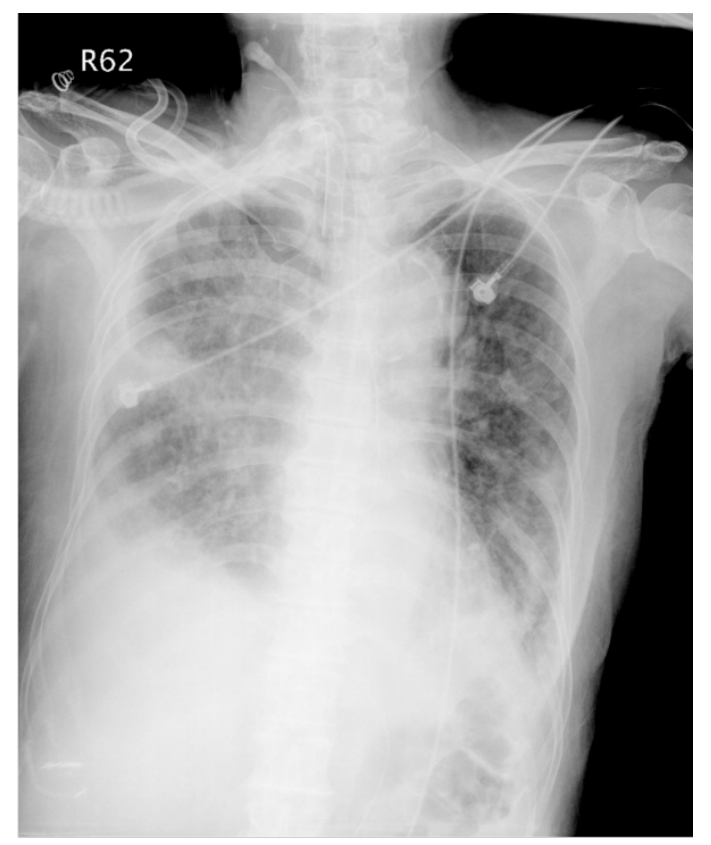

(B)

Figure 3. Case of a patient who experienced a dramatic response to EGFR-TKI during ICU treatment. This 72-year-old woman had right lung adenocarcinoma, cT4N3M1c, stage IVB, with malignant pleural effusion, lung-to-lung, liver, and adrenal metastasis. She suffered from an episode of pneumonia and hypercapnic respiratory failure, and was admitted to the ICU for intensive care. The plain film before (A) and 2 weeks after gefitinib (B) are shown. The patient finally was weaned successfully from the mechanical ventilator and discharged home with tracheostomy under ambient air. Acronyms: EGFR = epidermal growth factor receptor, ICU = intensive care unit, TKI = tyrosine kinase inhibitor.

\subsection{Treatment Toxicity in the ICU}

Interstitial pneumonitis developed in two patients $(6 \%)$, of whom one used gefitinib and one used erlotinib. TKI was withheld, but one patient (treated with erlotinib) still died despite systemic steroid treatments. Other adverse events, including diarrhea (2 of 35, 6\%), hepatitis ( 1 of $35,3 \%$ ), and skin toxicity ( 4 of $35,11 \%$ ), occurred, but did not exceed grade 3 ; thus, TKI treatment was kept without interruption. 


\subsection{Patient Deposition after ICU Discharge}

Of the 27 patients who survived up to the 28th day after ICU admission, 18 were successfully discharged from the hospital. The median length of stay was 21 (interquartile range: 15-31) days in the ICU and 42 (interquartile range: 33-68) days in the hospital. In addition, eight patients returned home without MV use, one returned home with MV use, one was transferred to a long-term respiratory care unit with MV use, and one patient was transferred to a nursing home.

\section{Discussion}

For lung cancer patients suffering from respiratory failure and admitted to the ICU, administration of an effective anti-cancer therapy, in addition to critical care management, is crucial. Our study showed that TKIs could prolong ICU survival in EGFR-driven lung cancer, even for those patients with a critical illness requiring MV. Patients who harbor EGFR exon 19 deletion, who were hemodynamically stable, and who had no DM comorbidity may benefit more from EGFR TKI. To our knowledge, this is the largest cohort to date that substantiates the benefit of EGFR-TKI use for lung cancer patients in such a setting.

In the past, the benefits of medical ICU admission and MV for critically ill lung cancer patients were held in doubt $[3,26-29]$. The overall ICU and in-hospital mortality rates in our study group were only $23 \%$ and $51 \%$, respectively. Mortality in our study group was less than that of previous studies on the survival of lung cancer patients admitted to the medical ICU with MV use, in which ICU mortality ranged from 40 to $60 \%$ and in-hospital mortality ranged from 50 to $80 \%$ [3,26-31]. As reported in studies prior to 2010, best supportive care was the main treatment strategy for lung cancer patients [3]. In our study, all patients who received EGFR-TKI therapy were documented to harbor a sensitizing EGFR mutation. The better survival in our study was probably due to the use of EGFR-TKIs, and the additional benefits in the del19 subgroup were also consistent with the results in clinical trials $[11,32]$. Otherwise, DM is another risk factor found in our study to predict weaning failure. Though plenty of researchers have demonstrated the disadvantage of DM in critically ill patients [33], the specific impact on weaning is still undetermined [34] and needs larger studies to clarify.

With the advent of the era of TKIs, treatment for lung cancer patients with a poor performance status changed [9]. Several small case series reported the efficacy of TKIs in lung cancer patients admitted to the medical ICU. Some studies evaluated the efficacy of EGFR-TKIs for NSCLC patients admitted to the ICU with MV use [6]. Hsia et al. reported a study that enrolled 83 patients, of whom only 23 were treated with EGFR-TKIs in 2014. The use of EGFR-TKIs made no difference in hospital mortality ( $68 \%$ vs. $61 \%, p=0.81)$ and weaning rate $(18 \%$ vs. $22 \%, p=0.81)$ in the standard care and TKI groups. Instead, the SAPS and SOFA scores were significant predictors of weaning outcome. Toffart et al. (2015) reported that the use of TKIs had no impact on early mortality, but improved survival for those at a late phase (28 days after ICU admission) only [35]. These previous results suggested that weaning and mortality were determined by the severity of the critical illness. None of them demonstrated the independent prognostic role of EGFR mutation in the setting of TKI treatment for lung cancer patients admitted to the ICU due to respiratory failure. Kerrigan et al. [17] and Chen et al. [36] also reported the use of TKIs with critically ill lung cancer patients, but the case number of patients with a documented mutation status in the two studies was only nine and one, respectively (Table 5). 
Table 5. Summary of prior studies of EGFR-TKI use for lung cancer patients admitted to intensive care units.

\begin{tabular}{|c|c|c|c|}
\hline Studies & Patient Population & Treatment & Outcomes \\
\hline The present study & $\begin{array}{l}\text { EGFR mutation: } 35 \text {, EGFR } \\
\text { wild-type: } 28\end{array}$ & All received EGFR-TKI & $\begin{array}{l}\text { EGFR mutation vs. wild-type: } \\
\text { 28-day ICU survival rate: } 77 \% \text { vs. } 50 \% \text {, } \\
p=0.025 \\
\text { Median overall survival: } 67 \text { vs. } 28 \text { days, } \\
p=0.01 \\
\text { Rate of weaning from MV: } 43 \% \text { vs. } 25 \% \text {, } \\
\quad p=0.14\end{array}$ \\
\hline Hsia et al. [6] & $\begin{array}{l}n=83 \text { (EGFR: } 6 \text { ) } \\
\text { Respiratory failure }\end{array}$ & $\begin{array}{l}\text { EGFR-TKI: } 23 \\
\text { (6 with confirmed } \\
\text { EGFR mutation) }\end{array}$ & $\begin{array}{l}\text { Rate of weaning from MV: } \\
\text { Standard care vs. EGFR-TKI: } 18 \% \text { vs. } 22 \% \text {, } \\
\qquad p=0.81\end{array}$ \\
\hline Toffart AC et al. [35] & $\begin{array}{c}n=14 \text { (EGFR:5, ALK: 8, ROS1: 1) } \\
\text { Respiratory failure (MV: 9, NIPPV: 4) }\end{array}$ & All received TKI & $\begin{array}{c}\text { ICU survival rate } 57 \% \\
\text { Median overall survival: } 91 \text { days } \\
\text { Longer late survival versus } \\
\text { histological control: } \\
\text { HR } 0.12, p=0.002\end{array}$ \\
\hline Kerrigan et al. [17] & $\begin{array}{l}\quad n=9 \text { (EGFR: 3, ALK: 3, ROS1: 1, } \\
\text { MET: 1, unknown: 1) } \\
\text { Respiratory failure (MV: 6, NIPPV: 3) }\end{array}$ & $\begin{array}{l}\text { EGFR: Erlotinib: } 3 \\
\text { ALK: Crizotinib: 1, } \\
\text { Ceritinib: 1, erlotinib } 1 \\
\text { ROS1: Crizotinib: } 1 \\
\text { MET: Crizotinib: } 1 \\
\text { Unknown: Erlotinib: } 1\end{array}$ & $\begin{array}{c}\text { Rate of weaning from MV: } 3 \text { of } 9(33 \%) \\
\text { ICU mortality rate: } 56 \%\end{array}$ \\
\hline Chen et al. [36] & $\begin{array}{c}n=72 \text { (EGFR was confirmed in only } \\
1 \text { case) }\end{array}$ & $\begin{array}{l}\text { EGFR-TKI: } 24 \text { ( } 1 \text { with } \\
\text { confirmed EGFR mutation) }\end{array}$ & $\begin{array}{l}\text { ICU survival was better in patients receiving } \\
\text { chemotherapy or EGFR-TKI vs. BSC } \\
\qquad(p=0.011)\end{array}$ \\
\hline
\end{tabular}

With regard to safety concerns, the incidence of interstitial pneumonitis was mildly higher than previously reported in the IPASS, EURTAC and LUX-LUNG6 studies $(0 \%, 1 \%$, and $0 \%$, separately) $[11,32,37,38]$. One Japanese observational cohort with 3166 patients reported that the incidence of interstitial pneumonitis was $4 \%$ in the gefitinib group and $2.1 \%$ in the chemotherapy group [39]. The reported risks included: older age, poor performance status, smoking, recent lung cancer diagnosis, pre-existing chronic interstitial lung disease. However, in previous studies on TKI use in ICU lung cancer patients, adverse events were not mentioned clearly. In our study, two patients were diagnosed with interstitial pneumonitis. One was diagnosed by chest CT and erlotinib was then held. The other patient developed desaturation during treatment and their condition improved after steroid and antibiotics treatment with successful rechallenge of gefitinib. Although the diagnosis of TKI-related interstitial pneumonitis was not certain and the development of interstitial pneumonitis was not significantly related to survival in our study, the relatively higher incidence of possible interstitial pneumonitis in lung cancer patients with respiratory failure should be kept in mind. On the other hand, our study still revealed the benefit of the higher weaning rate in the patients receiving effective treatment. In addition, withholding EGFR TKI in cases without evidence of drug resistance during ICU admission could lead to disease recurrence. Previous studies on patients without any TKI-related toxicity found that $5-25 \%$ of the patients experienced disease flare-up after discontinuation of TKI [40-42]. According to the ASCO expert panel discussion in 2017, to stop the administration of EGFR TKI is reasonable only if there is apparent disease progression or intolerable side effects [43]. In the aspect of alternative treatment, immunotherapy also can cause severe immune-related adverse events in $20 \%$ of patients [44], and there was some evidence that revealed the limited efficacy of immunotherapy in patients with poor performance status [45]. Immune checkpoint inhibitors are also less effective in EGFR mutant lung cancer, precluding a useful application for these patients in the ICU setting [46]. According to our study results, it is worth administering EGFR-TKIs for patients who are detected as EGFR mutation while they are undergoing MV in ICU, and TKI should be withheld if there is any suspicion of TKI-related interstitial pneumonitis clinically.

There are several limitations in our study. First, this is a retrospective study performed in a single center. Though the case number is small, our study is the largest cohort of EGFR mutant lung cancer patients admitted to ICU with ventilator support. The EGFR mutation 
status and TKI-related outcomes were clearly documented and described. Second, many heterogeneities still existed in ICU patients despite multivariate adjustment. It is probably inapplicable to conduct a clinical trial to address the efficacy of EGFR TKI in the ICU setting; hence, our results might provide prognostic information for these patients in real world practice.

\section{Conclusions}

In conclusion, our study is currently the largest cohort to reveal the potential benefit of EGFR-TKIs use in NSCLC patients harboring a sensitizing EGFR mutation, especially the del19 subgroup, who were admitted to the ICU due to respiratory failure. Though sometimes difficult, obtaining a molecular profile using either tissue or liquid biopsy should be a mandatory approach to managing lung cancer patients with potential targetable driver mutations, even those in a critical status.

Supplementary Materials: The following are available online at https:/ /www.mdpi.com/article/10 $.3390 /$ biomedicines $9101416 /$ s1, Figure S1: Survival and rate of successful weaning from mechanical ventilation of lung cancer patients receiving EGFR-TKIs in the ICU, Table S1: Demographic data of EGFR-TKI-treated NSCLC patients who were admitted to the ICU and received mechanical ventilation, Table S2: Treatment outcomes relevant to EGFR-TKIs.

Author Contributions: Conceptualization, I.-H.L. and C.-Y.Y.; methodology, I.-H.L. and C.-Y.Y.; formal analysis, I.-H.L.; investigation, I.-H.L.; resources, J.-Y.S. and C.-J.Y.; data curation, I.-H.L. and C.-Y.Y.; writing — original draft preparation, I.-H.L.; writing—review and editing, C.-Y.Y.; visualization, I.-H.L.; supervision, C.-Y.Y., J.-Y.S. and C.-J.Y. All authors have read and agreed to the published version of the manuscript.

Funding: This research received no external funding.

Institutional Review Board Statement: The study was conducted according to the guidelines of the Declaration of Helsinki, and approved by the Institutional Review Board (or Ethics Committee) of National Taiwan University Hospital (201802015RINB).

Informed Consent Statement: Patient consent was waived because we only performed retrospective data collection and the to-be-published content will not involve the identification of the participating patients.

Data Availability Statement: All data are included in this manuscript.

Conflicts of Interest: The authors declare no conflict of interest.

\section{References}

1. Soares, M.; Caruso, P.; Silva, E.; Teles, J.M.; Lobo, S.M.; Friedman, G.; Dal Pizzol, F.; Mello, P.V.; Bozza, F.A.; Silva, U.V.; et al. Characteristics and outcomes of patients with cancer requiring admission to intensive care units: A prospective multicenter study. Crit. Care Med. 2010, 38, 9-15. [CrossRef] [PubMed]

2. Azoulay, E.; Moreau, D.; Alberti, C.; Leleu, G.; Adrie, C.; Barboteu, M.; Cottu, P.; Levy, V.; Le Gall, J.R.; Schlemmer, B. Predictors of short-term mortality in critically ill patients with solid malignancies. Intensive Care Med. 2000, 26, 1817-1823. [CrossRef] [PubMed]

3. Slatore, C.G.; Cecere, L.M.; Letourneau, J.L.; O’Neil, M.E.; Duckart, J.P.; Wiener, R.S.; Farjah, F.; Cooke, C.R. Intensive care unit outcomes among patients with lung cancer in the surveillance, epidemiology, and end results-medicare registry. J. Clin. Oncol. 2012, 30, 1686-1691. [CrossRef] [PubMed]

4. Soares, M.; Toffart, A.C.; Timsit, J.F.; Burghi, G.; Irrazabal, C.; Pattison, N.; Tobar, E.; Almeida, B.F.; Silva, U.V.; Azevedo, L.C.; et al. Intensive care in patients with lung cancer: A multinational study. Ann. Oncol. Off. J. Eur. Soc. Med. Oncol. 2014, 25, $1829-1835$. [CrossRef] [PubMed]

5. Adam, A.K.; Soubani, A.O. Outcome and prognostic factors of lung cancer patients admitted to the medical intensive care unit. Eur. Respir. J. 2008, 31, 47-53. [CrossRef] [PubMed]

6. Hsia, T.C.; Tu, C.Y.; Chen, H.J. The impact of rescue or maintenance therapy with EGFR TKIs for Stage IIIb-IV non-squamous non-small-cell lung cancer patients requiring mechanical ventilation. BMC Anesth. 2014, 14, 55. [CrossRef]

7. Benoit, D.D.; Soares, M.; Azoulay, E. Has survival increased in cancer patients admitted to the ICU? We are not sure. Intensive Care Med. 2014, 40, 1576-1579. [CrossRef] [PubMed] 
8. Lin, Y.C.; Tsai, Y.H.; Huang, C.C.; Hsu, K.H.; Wang, S.W.; Tsao, T.C.; Lin, M.C. Outcome of lung cancer patients with acute respiratory failure requiring mechanical ventilation. Respir. Med. 2004, 98, 43-51. [CrossRef] [PubMed]

9. Inoue, A.; Kobayashi, K.; Usui, K.; Maemondo, M.; Okinaga, S.; Mikami, I.; Ando, M.; Yamazaki, K.; Saijo, Y.; Gemma, A.; et al. First-line gefitinib for patients with advanced non-small-cell lung cancer harboring epidermal growth factor receptor mutations without indication for chemotherapy. J. Clin. Oncol. 2009, 27, 1394-1400. [CrossRef]

10. Soubani, A.O.; Ruckdeschel, J.C. The Outcome of Medical Intensive Care for Lung Cancer Patients: The Case for Optimism. J. Thorac. Oncol. 2011, 6, 633-638. [CrossRef]

11. Mok, T.S.; Wu, Y.-L.; Thongprasert, S.; Yang, C.-H.; Chu, D.-T.; Saijo, N.; Sunpaweravong, P.; Han, B.; Margono, B.; Ichinose, Y.; et al. Gefitinib or Carboplatin-Paclitaxel in Pulmonary Adenocarcinoma. N. Engl. J. Med. 2009, 361, 947-957. [CrossRef]

12. Shepherd, F.A.; Rodrigues Pereira, J.; Ciuleanu, T.; Tan, E.H.; Hirsh, V.; Thongprasert, S.; Campos, D.; Maoleekoonpiroj, S.; Smylie, M.; Martins, R.; et al. Erlotinib in Previously Treated Non-Small-Cell Lung Cancer. N. Engl. J. Med. 2005, 353, 123-132. [CrossRef]

13. Park, K.; Tan, E.H.; O’Byrne, K.; Zhang, L.; Boyer, M.; Mok, T.; Hirsh, V.; Yang, J.C.; Lee, K.H.; Lu, S.; et al. Afatinib versus gefitinib as first-line treatment of patients with EGFR mutation-positive non-small-cell lung cancer (LUX-Lung 7): A phase 2B, open-label, randomised controlled trial. Lancet Oncol. 2016, 17, 577-589. [CrossRef]

14. Soria, J.-C.; Ohe, Y.; Vansteenkiste, J.; Reungwetwattana, T.; Chewaskulyong, B.; Lee, K.H.; Dechaphunkul, A.; Imamura, F.; Nogami, N.; Kurata, T.; et al. Osimertinib in Untreated EGFR-Mutated Advanced Non-Small-Cell Lung Cancer. N. Engl. J. Med. 2017, 378, 113-125. [CrossRef]

15. Bosch-Barrera, J.; Sais, E.; Lorencio, C.; Porta, R.; Izquierdo, A.; Menendez, J.A.; Brunet, J.; Sirvent, J.M.; Rosell, R. Successful empirical erlotinib treatment of a mechanically ventilated patient newly diagnosed with metastatic lung adenocarcinoma. Lung Cancer 2014, 86, 102-104. [CrossRef]

16. Chien, C.R.; Chen, H.J. Lazarus response to treatment of patients with lung cancer and oncogenic mutations in the intensive care unit. J. Thorac. Dis. 2016, 8, E1455-E1461. [CrossRef]

17. Kerrigan, K.; Shoben, A.; Otterson, G. Treatment of Lung Cancer Patients With Actionable Mutations in the Intensive Care Unit. Clin. Lung Cancer 2016, 17, 523-527. [CrossRef] [PubMed]

18. Dewolf, M.; Dayen, C.; Garoute, C.; Khamis, W.; Fourrier, M.; Rousselle, F.; Sadki, M.; Le Meunier, F.; Suguenot, R.; Lecuyer, E.; et al. Effectiveness of erlotinib in Critical Care Unit in patients with non-small cell lung cancer with EGFR mutation. Rev. Pneumol. Clin. 2017, 73, 135-139. [CrossRef] [PubMed]

19. Guillon, A.; Reckamp, K.L.; Heuze-Vourc'h, N. Immunotherapy improves the prognosis of lung cancer: Do we have to change intensive care unit admission and triage guidelines? Crit. Care 2017, 21, 18. [CrossRef] [PubMed]

20. Reck, M.; Rodríguez-Abreu, D.; Robinson, A.G.; Hui, R.; Csőszi, T.; Fülöp, A.; Gottfried, M.; Peled, N.; Tafreshi, A.; Cuffe, S.; et al. Pembrolizumab versus Chemotherapy for PD-L1-Positive Non-Small-Cell Lung Cancer. N. Engl. J. Med. 2016, 375, 1823-1833. [CrossRef] [PubMed]

21. Lin, S.Y.; Yang, C.Y.; Liao, B.C.; Ho, C.C.; Liao, W.Y.; Chen, K.Y.; Tsai, T.H.; Hsu, C.L.; Hsu, W.H.; Su, K.Y.; et al. Tumor PD-L1 Expression and Clinical Outcomes in Advanced-stage Non-Small Cell Lung Cancer Patients Treated with Nivolumab or Pembrolizumab: Real-World Data in Taiwan. J. Cancer 2018, 9, 1813-1820. [CrossRef] [PubMed]

22. Emens, L.A.; Ascierto, P.A.; Darcy, P.K.; Demaria, S.; Eggermont, A.M.M.; Redmond, W.L.; Seliger, B.; Marincola, F.M. Cancer immunotherapy: Opportunities and challenges in the rapidly evolving clinical landscape. Eur. J. Cancer 2017, 81, 116-129. [CrossRef] [PubMed]

23. Christofi, T.; Baritaki, S.; Falzone, L.; Libra, M.; Zaravinos, A. Current Perspectives in Cancer Immunotherapy. Cancers 2019, 11, 1472. [CrossRef] [PubMed]

24. Falzone, L.; Salomone, S.; Libra, M. Evolution of Cancer Pharmacological Treatments at the Turn of the Third Millennium. Front. Pharmacol. 2018, 9, 1300. [CrossRef] [PubMed]

25. Assi, H.I.; Kamphorst, A.O.; Moukalled, N.M.; Ramalingam, S.S. Immune checkpoint inhibitors in advanced non-small cell lung cancer. Cancer 2018, 124, 248-261. [CrossRef]

26. Soares, M.; Azoulay, E. Critical care management of lung cancer patients to prolong life without prolonging dying. Intensive Care Med. 2009, 35, 2012-2014. [CrossRef]

27. Andrejak, C.; Terzi, N.; Thielen, S.; Bergot, E.; Zalcman, G.; Charbonneau, P.; Jounieaux, V. Admission of advanced lung cancer patients to intensive care unit: A retrospective study of 76 patients. BMC Cancer 2011, 11, 159. [CrossRef]

28. Bonomi, M.R.; Smith, C.B.; Mhango, G.; Wisnivesky, J.P. Outcomes of elderly patients with stage IIIB-IV non-small cell lung cancer admitted to the intensive care unit. Lung Cancer 2012, 77, 600-604. [CrossRef]

29. Chou, K.T.; Chen, C.S.; Su, K.C.; Hung, M.H.; Hsiao, Y.H.; Tseng, C.M.; Chen, Y.M.; Lee, Y.C.; Perng, D.W. Hospital outcomes for patients with stage III and IV lung cancer admitted to the intensive care unit for sepsis-related acute respiratory failure. J. Palliat. Med. 2012, 15, 1234-1239. [CrossRef]

30. Chang, Y.; Huh, J.W.; Hong, S.B.; Lee, D.H.; Suh, C.; Kim, S.W.; Lim, C.M.; Koh, Y. Outcomes and prognostic factors of patients with lung cancer and pneumonia-induced respiratory failure in a medical intensive care unit: A single-center study. J. Crit. Care 2014, 29, 414-419. [CrossRef]

31. Kim, Y.J.; Kim, M.J.; Cho, Y.J.; Park, J.S.; Kim, J.W.; Chang, H.; Lee, J.O.; Lee, K.W.; Kim, J.H.; Yoon, H.I.; et al. Who should be admitted to the intensive care unit? The outcome of intensive care unit admission in stage IIIB-IV lung cancer patients. Med. Oncol. 2014, 31, 847. [CrossRef] 
32. Rosell, R.; Carcereny, E.; Gervais, R.; Vergnenegre, A.; Massuti, B.; Felip, E.; Palmero, R.; Garcia-Gomez, R.; Pallares, C.; Sanchez, J.M.; et al. Erlotinib versus standard chemotherapy as first-line treatment for European patients with advanced EGFR mutationpositive non-small-cell lung cancer (EURTAC): A multicentre, open-label, randomised phase 3 trial. Lancet Oncol. 2012, 13, 239-246. [CrossRef]

33. Siegelaar, S.E.; Hickmann, M.; Hoekstra, J.B.; Holleman, F.; DeVries, J.H. The effect of diabetes on mortality in critically ill patients: A systematic review and meta-analysis. Crit. Care 2011, 15, R205. [CrossRef]

34. Shin, H.J.; Chang, J.S.; Ahn, S.; Kim, T.O.; Park, C.K.; Lim, J.H.; Oh, I.J.; Kim, Y.I.; Lim, S.C.; Kim, Y.C.; et al. Clinical factors associated with weaning failure in patients requiring prolonged mechanical ventilation. J. Thorac. Dis. 2017, 9, 143-150. [CrossRef] [PubMed]

35. Toffart, A.C.; Dhalluin, X.; Girard, N.; Chouaid, C.; Audigier-Valette, C.; Duruisseaux, M.; Mennecier, B.; Parrot, A.; Fournel, P.; Moro-Sibilot, D.; et al. Patients with advanced lung cancer harboring oncogenic mutations should be admitted to intensive care units. Intensive Care Med. 2015, 41, 164-165. [CrossRef] [PubMed]

36. Chen, Y.F.; Lin, J.W.; Ho, C.C.; Yang, C.Y.; Chang, C.H.; Huang, T.M.; Chen, C.Y.; Chen, K.Y.; Shih, J.Y.; Yu, C.J. Outcomes of cancer therapy administered to treatment-naive lung cancer patients in the intensive care unit. J. Cancer 2017, 8, 1995-2003. [CrossRef] [PubMed]

37. Wu, Y.-L.; Zhou, C.; Hu, C.-P.; Feng, J.; Lu, S.; Huang, Y.; Li, W.; Hou, M.; Shi, J.H.; Lee, K.Y.; et al. Afatinib versus cisplatin plus gemcitabine for first-line treatment of Asian patients with advanced non-small-cell lung cancer harbouring EGFR mutations (LUX-Lung 6): An open-label, randomised phase 3 trial. Lancet Oncol. 2014, 15, 213-222. [CrossRef]

38. Lee, S.M.; Khan, I.; Upadhyay, S.; Lewanski, C.; Falk, S.; Skailes, G.; Marshall, E.; Woll, P.J.; Hatton, M.; Lal, R.; et al. Firstline erlotinib in patients with advanced non-small-cell lung cancer unsuitable for chemotherapy (TOPICAL): A double-blind, placebo-controlled, phase 3 trial. Lancet Oncol. 2012, 13, 1161-1170. [CrossRef]

39. Kudoh, S.; Kato, H.; Nishiwaki, Y.; Fukuoka, M.; Nakata, K.; Ichinose, Y.; Tsuboi, M.; Yokota, S.; Nakagawa, K.; Suga, M.; et al. Interstitial lung disease in Japanese patients with lung cancer: A cohort and nested case-control study. Am. J. Respir. Crit. Care Med. 2008, 177, 1348-1357. [CrossRef] [PubMed]

40. Chaft, J.E.; Oxnard, G.R.; Sima, C.S.; Kris, M.G.; Miller, V.A.; Riely, G.J. Disease flare after tyrosine kinase inhibitor discontinuation in patients with EGFR-mutant lung cancer and acquired resistance to erlotinib or gefitinib: Implications for clinical trial design. Clin. Cancer Res. Off. J. Am. Assoc. Cancer Res. 2011, 17, 6298-6303. [CrossRef]

41. Chen, H.J.; Yan, H.H.; Yang, J.J.; Chen, Z.H.; Su, J.; Zhang, X.C.; Wu, Y.L. Disease flare after EGFR tyrosine kinase inhibitor cessation predicts poor survival in patients with non-small cell lung cancer. Pathol. Oncol. Res. POR 2013, 19, 833-838. [CrossRef] [PubMed]

42. Akamatsu, H.; Ono, A.; Shukuya, T.; Tsuya, A.; Nakamura, Y.; Kenmotsu, H.; Naito, T.; Murakami, H.; Endo, M.; Nakajima, T.; et al. Disease flare after gefitinib discontinuation. Respir. Investig. 2015, 53, 68-72. [CrossRef] [PubMed]

43. Smith, T.J.; Hanna, N.; Johnson, D.; Jr, S.B.; Biermann, W.A.; Brahmer, J.; Ellis, P.M.; Giaccone, G.; Hesketh, P.J.; Jaiyesimi, I.; et al. Case for Stopping Targeted Therapy When Lung Cancer Progresses on Treatment in Hospice-Eligible Patients. J. Oncol. Pract. 2017, 13, 780-783. [CrossRef]

44. Lemiale, V.; Meert, A.P.; Vincent, F.; Darmon, M.; Bauer, P.R.; Van de Louw, A.; Azoulay, E. Severe toxicity from checkpoint protein inhibitors: What intensive care physicians need to know? Ann. Intensive Care 2019, 9, 25. [CrossRef]

45. Facchinetti, F.; Mazzaschi, G.; Barbieri, F.; Passiglia, F.; Mazzoni, F.; Berardi, R.; Proto, C.; Cecere, F.L.; Pilotto, S.; Scotti, V.; et al. First-line pembrolizumab in advanced non-small cell lung cancer patients with poor performance status. Eur. J. Cancer 2020, 130, 155-167. [CrossRef]

46. Lee, C.K.; Man, J.; Lord, S.; Links, M.; Gebski, V.; Mok, T.; Yang, J.C. Checkpoint Inhibitors in Metastatic EGFR-Mutated Non-Small Cell Lung Cancer-A Meta-Analysis. J. Thorac. Oncol. 2017, 12, 403-407. [CrossRef] [PubMed] 